\title{
Enhanced Photodegradation of Methyl Orange with ZnS Nanoparticles
}

\author{
S. Suganya, M. Jothibas ${ }^{1 *}$, A. Muthuvel ${ }^{2}$ \\ PG \& Research Department of Physics T B M L College, Porayr-609307, Tamilnadu, India \\ *Corresponding Author: jothibas1980@gmail.com
}

Available online at: www.isroset.org

Received: 09/Nov/2018, Accepted: 22/Dec/2018, Online: 31/Dec/2018

\begin{abstract}
In this analysis, ZnS nanoparticles have been synthesized by (2, 4 and 6 hours) different hours by solid state reaction method. The obtained ZnS nanoparticles have been characterized through XRD, FTIR, UV-Visible, PL, SEM and TEM measurements. The foremost intense broad peaks in the diffraction outline reveal the crystalline nature of prepared samples with the crystal size is approximately $3.68 \mathrm{~nm}$. The optical bandgap has been evaluvated in the Uv-Vis. absorption spectrum which is found to be about $3.66 \mathrm{eV}$. The PL emission shows the blue green emission. SEM and TEM show the spherical shape of the $\mathrm{ZnS}$ nanoparticles. Photocatalytic activity of $\mathrm{ZnS}$ was evaluated by irradiating the solution of natural dye methyl orange (MO) in presence of solar light.
\end{abstract}

Keyword- ZnS nanoparticles, Photocatalytic activity, Methyl Orange.

\section{INTRODUCTION}

In recent years, Nano devices have substantially modified the optical,magnetic photocatlytic properties of nanotechnology, according to the study of intensive research for their use to create nano-devices [1]. Zinc Sulfide is a direct convertible semiconductor with a large band gap in the secondary and six semiconductors [2-3]. ZnS is an imperative mineral material for many types of applications, including optical finish, solid state solar cell windows, power optic converters, photoconductors, field effect transistors, sensors and light emitting diodes [4]. single or more nitrogen-tonerogens double bonds $(\mathrm{N}=\mathrm{N})$ are many times used in textiles, paper, leather, cosmetics and other industries.They are many times used in all shades, but their intermediate item, aerosol dyes and aromatic acids, toxins and toxins and humans for humans [5-7]. Recently, the abatement of waste to waste, biological degeneration and the electrochemical process to reduce various treatments. Process and photocatalytic degradation study,the photocatalytic method is solitary of the mainly determination of degradation technologies. biological compounds immediately and ultimately causes harmful carbon dioxide and water [8,9]. Photocatalytic procedure, photocatalytic reactions occur first when the target pollutant is absorbed on the exterior catalysis [10,11]. The low density of organic pollution can enrich it by osurcaching photocatalytic efficiency. Therefore, photocatalist preparation is extremely essential with huge exterior area, improving the effectiveness of photocatalytic degeneration of organic pollution [12]. The solar photacalytic system is used to make orange oxidation in the chest. Many techniques are used to integrate $\mathrm{ZnS}$ nanoparticles chemical vapor deposition [13], wet chemical route [14], gas phase condensation method [15], co-precipitation method [16], solvothermal synthesis [17], hydrothermal process [18] thermal decomposition method [19] radio frequency magnetron sputtering technique [20] and solid state reaction method. These method is easy, simple, lowest cost and handy to perform Among that many researchers have analyzed the properties of $\mathrm{ZnS}$ nanoparticles into various method but only few researcher focused solid state reaction method. In these present work, Zinc sulfide nanoparticles are synthesized at different hours. The XRD, UV-Vis, PL, SEM, TEM, techniques have been adapted to characterize the synthesized ZnS nanoparticles and photocatalaytic activity.

Organization of this research papers done into five sections: Introduction, Related work, Materials and Methods, Results with discussion and Conclusions. Introduction section provides brief explain of present study.Various researcher studies on photocatalytic degradation of $\mathrm{ZnS}$ nanoparticles in related work section. Materials and methods sections contain precursors and chemicals for synthesized $\mathrm{ZnS}$ nanoparticles and characterization techniques employed for the analysis of $\mathrm{ZnS}$ nanoparticles by solid state reaction method. Results and discussion provides a brief on the characterization of $\mathrm{ZnS}$ nanoparticles and the analysis. Conclusion section provides the major conclusions drrawn from the results.

\section{II.RELATED WORK}

There are some reports on the enhanced photocatalytic degradation of methyl orange with ZnS nanoparticles. Some of the related works done by various researchers are, Zhiyuan Ye et.al.2018 [21] reported a comparative study of photocatalytic 
activity of $\mathrm{ZnS}$ photocatalyst for degradation of various dyes. Fengjuan Chen et.al. 2013 [22] reported a facile route for the synthesis of $\mathrm{ZnS}$ rods with excellent photocatalytic activity. Mohd Mubashshir Hasan Farooqi et.al.2013 [23] Structural, optical and photoconductivity study of ZnS nanoparticles synthesized by a low temperature solid state reaction method. G. G. Ramteke.et.al.2018 [24] Structural and Optical Performance of ZnS Nanoparticles Synthesized via Chemical Route. P.P.Subha et.al.2015 [25] solar photo catalytic degradation of methyl orange dye using TiO2 nanoparticles synthesised by sol-gel method in neutral medium.

\section{III.MATERIALS AND METHODS}

\section{A. Experimental}

In this study, Zinc acetate dehydrate and thiourea is used to form $\mathrm{ZnS}$ nanoparticles. These chemicals were directly used without special treatment. In typical synthesis Zinc acetate dehydrate and thiourea are ground throughly. Finally mixed powder was transfer to crucible and powder was calcinated in a muffle furnace for $400^{\circ} \mathrm{C}$ at different hours 2,4 and $6 \mathrm{~h}$ respectively. The prepared $\mathrm{ZnS}$ nanopowder is shown in Figure 1. This method was also adopted by Wang and Hang [26] to prepare ZnS nanoparticles.

\section{B. Characterization of $\mathbf{Z n S}$ nanoparticles.}

The crystal structure and phase of ZnS nanopowder were studied by X-ray diffraction analysis using SHIMADZUXRD 6000. The morphology of the samples was characterized by SEM (Hitachi S-4500 SEM Machine) and TEM analyses.The absorption spectra were measured using UV-Vis spectrophotometer (SHIMADZU-UV 1800). The PL spectrum was recorded on a fluorescence spectrophotometer with an excitation wavelength of $325 \mathrm{~nm}$ at room temperature.

\section{Photocatalytic Experiments}

Photocatalytic decomposition of Methyl Orange was examined by optical absorption spectroscopy. Degradation experiments be accomplish by adding $0.06 \mathrm{~g}$ of $\mathrm{ZnS}$ in to $100 \mathrm{ml}$ of $10 \mathrm{mg} / \mathrm{lM}$ aqueous $\mathrm{MO}$ solution. The assemblage was sonicated and stirred in the gloomy in order to reach adsorption-desorption symmetry amid MO and dissolved oxygen before irradiation. The stirred suspensions were then irradiated with sunlight, and $5.0 \mathrm{ml}$ solution was drawn out in each 15 minutes. Then the deferral was kept under sunshine irradiation and the sample is taken-out for each $15 \mathrm{~min}$ (up to $75 \mathrm{~min}$ ).Because of the degradation of the dye the colour of the deferral changes from dark to light orange and then became colourless. This graphical abstract describe in general handling processes of dye infected water using the $\mathrm{ZnS}$ nanoparticles as shown in Figure 2. The concentration of MO dye in the samples was purposive using UV-Vis spectrophotometer.

\section{RESULT AND DISCUSSION}

\section{A. Structural analysis}

Powder X-ray diffraction patterns of pure $\mathrm{ZnS}$ nanoparticles synthesized at different hours (2,4 and $6 \mathrm{~h})$ at constant temperature $4000 \mathrm{C}$ with miller indices (hkl) viewing the crystal family of planes for apiece diffraction peaks are predicted shown in Figure 3. The intense diffraction peaks emerge at about $2 \theta$ of 28.700, 47.900 and 56.620 analogous with those from (111), (220) and (311) orientations, respectively [27] this spectra displays relatively low intensity reflections with a good deal (220) and (311) plane with strong priority orientation (111) plane has exhibit cubic crystal structure and coordinated with common JCPDS (05-0566) values of ZnS compounds. The XRD peaks are significantly expanded due to the small crystal size [28]. The average crystalline level is $2 \theta$ and the full width (FWHM),(hkl) peaks using Debye-Scherrer relation, the crystal size calculations are carried out from the Debye-Scherer relation $[29,30]$.

\section{$\mathrm{D}=\mathrm{K} \lambda / \beta \cos \theta$}

where, D is the average crystallite size $(\AA), \mathrm{K}$ is the shape factor $(0.9), \lambda$ is the wavelength of $\mathrm{X}$-ray $(1.5406 \AA) \mathrm{CuKa}$ radiation, $\theta$ is the Bragg angle and $B$ is the corrected line augmentation nanoparticles. The dislocation density $(\delta)$ is defined as the length of dislocation lines per unit volume of the crystal and was evaluated by using the relation.

$$
\delta=\frac{1}{\mathrm{D}^{2}}
$$

where, $\mathrm{D}$ is the quantity of crystal derived from XRD data and $\mathrm{n}$ is the factor that is equivalent to the low dislocation density. The dislocation density increases from $9.3416 \times 10^{14} \mathrm{line} / \mathrm{m}^{2}$ to $9.779610^{14} \mathrm{line} / \mathrm{m}^{2}$ for upto 4 hrs, dislocation density of Zinc Sulfide decreases due to an increase in hours (6h) about $9.1216 \mathrm{line} / \mathrm{m} 2$ has decreases is indicating imperfection in a crystal related with the dislocation of the lattice. Table 1.dislocation density of Zinc Sulfide decreases due to an increase in hours [31, 32].The microstrain $\varepsilon_{\mathrm{hkl}}$ in the synthesized sample was designed by using the relation [33].

$$
\varepsilon=\frac{\beta \cos \theta}{4}
$$


The lattice parameters a,b,c for the cubic structure can be determined by the following equation,

$$
d=\frac{a}{\sqrt{\mathrm{h}^{2}+\mathrm{k}^{2}+l^{2}}}
$$

where $\mathrm{h}, \mathrm{k}$ and $\mathrm{l}$ are the miller indices of the peak. The crystalline size of $\mathrm{ZnS}$ nanoparticles is specified in the Table 1 accumulated in three different hours. The calculated average lattice parameters were $5.4152 \AA, 5.4221 \AA$ and $5.3958 \AA \mathrm{nm}$. As the hours of precursors is increases lattice parameters are estimated to decrease. It can be perceive that 4 hours averaging a crystal size of $3.68 \mathrm{~nm}$ with the optimum and favorable parameter more than the other hours.

\section{B. Optical absorption study}

The absorption spectrum of prepared $\mathrm{ZnS}$ nanoparticles is described in three different hours $(2,4$ and 6 hours) as shown in Figure 4. All samples are on the edging edge of $418 \mathrm{~nm}$ [34].The absorbance co-efficient is premediated using the formula,

$$
\alpha=\frac{2.303 A}{l}
$$

where, $\mathrm{A}$ is the absorbance and 1 is the path length. The value of optical band gap is gritty from the absorption spectra using the Tauc relation [35]

$$
\alpha \mathrm{h} \gamma=\mathrm{A}(\mathrm{h} \gamma-\mathrm{Eg})^{\mathrm{n}}
$$

where, $\alpha$ is the absorption co-efficient, A is the stable having detach worth for dissimilar transition, h $\gamma$ is the photon energy and Eg is the band gap energy $\mathrm{n}$ depends ahead the nature of transition. The band interval is a negative number for $\mathrm{n}=2,3 / 2$ and 3 , so the relationship to the $\mathrm{ZnS}$ is $\mathrm{n}=1 / 2$, which confirms the permitted straight change. Figure 5 . Curves of $(\alpha \mathrm{h} \gamma)^{2}$ versus $\mathrm{h} \gamma$ for $\mathrm{ZnS}$ nanoparticles produced in different hours. Eg values are obtained directly by drawing the lines to the X-axis. The spacing of the energy gap measured from these layers is represented in Table 2. In this table, Eg values vary from ZnS nanoparticles to varying times from 3.41 to 3.83.Among the $\mathrm{ZnS}$ products, the nanoparticles with the pack at $6 \mathrm{~h}$ reveal the high band gap energy. Therefore, it has been taken as an appropriate mix of further investigations. After the electronic absorption progression, electrons in maximum-energy states revert to minimum-energy states at the equal group at the equal position in the Brillonion region $[36,37]$. Vibrating optical absorption margin and optical band interval energy are controlled.

\section{Photoluminescent Spectroscopy}

Photoluminescence is a vital tool to explore the quality of nanoparticles which depends on the size of the crystallites, morphology and chemical environment. PL Spectra of ZnS nanoparticles among different hours (2, 4 and 6 hours), excitation wavelength is around $325 \mathrm{~nm}$ as shown in Figure 6.In the Pl spectrum,two distinct peak was 422-487 nm[38-42]. The peak at $422 \mathrm{~nm}$ (blue) may be assign to the composition of the electrons from the conduction band and holes from the valence band. The emission green peak at $487 \mathrm{~nm}$ can be connected with sulfur vacancy(s). The $2 \mathrm{hrs}$ of $\mathrm{ZnS}$ peak was expanded to compare with $4 \mathrm{hrs}$ and $6 \mathrm{hrs}$ its indicating incorption of the samples.

\section{Morphological Characterization}

Using the SEM provided by EDX, Nanoparticles analysis ensured the metamorphosis, crystal size as well as structure for heavy $\mathrm{ZnS}$, and confirmed their chemical structure. Nano-size $\mathrm{ZnS}$ grains are well defined mesopores shown in Figure 7(a).These micrographs make sure the highest intensity is growing. Besides the standardized allocation of particles, they have a cluster of particles or particles. An extremely brief survey of these pictures reveals the incidence of well-defined particlesspherical geometric particles. The most concise analysis of these pictures reveals the incidence of well-defined particlesspherical geometric shapes. The EDX analysis Figure 7(b) clearly showed elements like Zn and Sulfide. This color contains strong X-ray peaks with $\mathrm{Zn} \mathrm{Ka}$ and $\mathrm{S} \mathrm{Ka}$, and we have noticed that atomic and weight percentage in Table 3. Zn and $\mathrm{S}$ are 40.34 at\%, $24.91 \mathrm{wt} \%$ and 59.66 at\% $75.09 \mathrm{wt} \%$ respectively.Figure7(c-e) surface occupancy plot (SOP) of the ZnS nanoparticles.

\section{E. Transmission Electron Microscope}

Morphological clarification was again confirmed via Transmission electron microscopy analysis. TEM is also worn for the size and crystallization model of particles are shown in Figure 8 ( $\mathrm{a}$ and b). The particle size in $\mathrm{ZnS}$ nanoparticle is $3.68 \mathrm{~nm}$. The shape of the particle is spherical shape and average particle size is $3.68 \mathrm{~nm}$. The SAED method relates to the reflections of three strong crystal planes (111), (220) and (311), the particles are well segregated and proven by some integration [43].Any other variable rings absorbed into the SAED methods confirm the cubic $\mathrm{ZnS}$ at the crucial stage, which is a good deal with the XRD results (05-0566) in Figure 8c. The lattice space involving the two fringes was found $0.35 \mathrm{~nm}$ of $\mathrm{ZnS}$ nanoparticles in Figure $8 \mathrm{~d}$. The TEM image of nanoparticles clearly evident that the small nanoparticles are gathered together and having small size of nanoparticles.

\section{F. Evaluvation of Photocatalytic activity}


To further Photocatalytic mechanism, possible photocatalytic system of Methyl Orange dye through ZnS nanoparticles below solar radiation. $\mathrm{ZnS}$ nanoparticles made by the pair $\left(\mathrm{e}^{-}\right)$hole $\left(\mathrm{h}^{+}\right)$pair. At the topmost of the $\mathrm{ZnS}$ nanoparticles with spectroscopic radiation, $\mathrm{e}^{-}$and $\mathrm{h}^{+}$can be caused by light radiation that can be seen by photovoltaic microorganisms, which are diluted with $\mathrm{ZnS}$ nanoparticles. The photocatalyze deoxidation procedure for $\mathrm{ZnS}$ nanoparticles can be compiled as follows from these principles and previous statements [21].

Electron hole pair generation

$$
\mathrm{ZnS}+\mathrm{h} \gamma \rightarrow \mathrm{e}^{-}+\mathrm{h}^{+}
$$

Surface trapping

$$
\mathrm{h}^{+}+\equiv \mathrm{ZnOH} \equiv \mathrm{ZnO}+\mathrm{H}^{+}
$$

electron -hole recombination

Production of hydroxyl radicals

$$
\begin{gathered}
\mathrm{e}^{-}+\mathrm{h}^{+} \rightarrow \mathrm{ZnS} \\
\mathrm{e}^{-}+\mathrm{ZnO}^{+}+\mathrm{H}^{+} \rightarrow \mathrm{ZnOH}
\end{gathered}
$$

$$
\begin{gathered}
\mathrm{h}^{+}+\mathrm{OH}^{-} \rightarrow . \mathrm{OH} \\
\mathrm{e}^{-}+\mathrm{O}_{2} \rightarrow . \mathrm{O}^{2-} \\
. \mathrm{O}^{2-}+2 \mathrm{H}^{+}+\mathrm{e}^{-} \rightarrow \mathrm{H}_{2} \mathrm{O}_{2} \\
2 \mathrm{e}^{-}+\mathrm{O}_{2}+2 \mathrm{H}^{+} \rightarrow \mathrm{H}_{2} \mathrm{O}_{2} \\
\mathrm{e}^{-}+\mathrm{H}_{2} \mathrm{O}_{2} \rightarrow . \mathrm{OH}+\mathrm{OH}^{-} \\
. \mathrm{O}^{2-}+\mathrm{H}_{2} \mathrm{O}_{2} \rightarrow . \mathrm{OH}+\mathrm{OH}^{-}+\mathrm{O}_{2} \\
. \mathrm{OH}+\text { dye } \rightarrow \text { degradation produc }
\end{gathered}
$$

$\mathrm{ZnS}$ nanoparticles with huge surface area reaction increase due to the high adsorption of MO. The absorption is measured at $268 \mathrm{~nm}$ and $464 \mathrm{~nm}$. Well-defined absorption strips were removed after 75 minutes in the occurrence of ZnS with sunlight [25].The degradation percentage $(\% \mathrm{D})$ of the $\mathrm{MO}$ dye can be calculated from the following equation,

$$
\% \mathrm{D}=\frac{\mathrm{C}_{0}-\mathrm{C}_{\mathrm{t}}}{\mathrm{C}_{0}} \times 100
$$

where, $\% \mathrm{D}$ is the degradation percentage, $\mathrm{C}_{0}$ is the preliminary concentration, $\mathrm{C}_{\mathrm{t}}$ is the After the radiation, the dye criterion is the favored time interval (0-75 min). Using the $\mathrm{ZnS}$ catalysis as a function of the wavelength $(200-700 \mathrm{~nm}) \mathrm{of} 0$, 15, 30, 45, 60 and 75 minutes at various intervals of Figure 9 shows the absorption spectrum of MO. The absorption of MO, which is centered on $268 \mathrm{~nm}$ and $464 \mathrm{~nm}$, had a disruption by monitoring the peak. The layers exhibit the highest absorption peak. The product of the $\mathrm{ZnS}$ catalyst in the degradation of MO dye results from 0 to 75 minutes from time intervals in Table 4 .

\section{G. Kinetic analysis}

It is understand that the degradation of natural dyes by photocatalysts mostly follows pseudo first-order kinetics [44].

$$
\ln \left(\mathrm{C}_{0} / \mathrm{C}_{\mathrm{t}}\right)=\mathrm{kKt}=\mathrm{kt}
$$

Or

$$
\mathrm{C}_{0}=\mathrm{C}_{0} \mathrm{e}^{-\mathrm{kt}}
$$

where, $\mathrm{k}$ is the reaction rate constant, $\mathrm{K}$ is the adsorption co-efficient of the reactant. Relation curve between ln $\left(\mathrm{C}_{0} / \mathrm{C}_{\mathrm{t}}\right)$ and time $(\mathrm{t})$ represents a direct line, the slope equals the noticeable first-order rate constant $\mathrm{k}$. The kinetics of photodegradation of MO dye by $\mathrm{ZnS}$ nanoparticles were studied and the results are shown in Figure 10. According to the pseudo-first-order rate equation, the rate constant $(\mathrm{k})$ for MO degradation by $\mathrm{ZnS}$ nanoparticles was determined.The plot of $\ln \left(\mathrm{C}_{0} / \mathrm{C}_{\mathrm{t}}\right)$ as a function of irradiation time gives the rate constant value $0.0078 \mathrm{~min}^{-1}$ in Figure11.Moreover, the appropriate compatibility coefficient $\left(\mathrm{R}^{2}\right)$ is also determined to be 0.9963 .

\section{CONCLUSION}

$\mathrm{ZnS}$ nanoparticles are successfully synthesized by simple solid state reaction method. The cystal size of the particles are determined using XRD results, the Strong preferred orientation along (111) plane and exhibit cubic type crystal structure. The crystal size is $3.68 \mathrm{~nm}$. The optical bandgap has been evaluvated in the Uv-Vis. absorption spectrum which is found to be about $3.66 \mathrm{eV}$. The Photoluminescence emission range is $422-487 \mathrm{~nm}$ of both blue and green emissions. The SEM and TEM analysis also confirm their spherical shape morphology. EDX spectrum expressed to Zn and S stiochiometry. The photocatalytic performance of $\mathrm{ZnS}$ nanoparticles was evaluated using methyl orange dye as contamination compound. From the results, it has been found that the degradation rate of MO dye is solar irradiation on sunlight along with ZnS nanoparticles. 


\section{REFERENCES}

[1]. Sheo.K.Mishra, Rajneesh.k.Srivastava, S.G.Prakash, Ragavendra, S.Yadev, A.C.Pandey, "Structural, optical and Photoconductivity characteristics of magnesed doped cadmium sulfide nanoparticles synthesized by co-preceipitation method",J.Alloys.compd.,Vol.513, pp. 118124,2012

[2]. K.Ichino, K.Ueyama, H.Kariya, N.Suzuki, M.Kitagawa, and H.Kobayashi, "Photoluminescence study of ZnS /ZnMgS single quantum wells", Appl.Phys., Lett.,Vol.74 pp.3486, 1999

[3]. H. Hiramatsu, H. Ohta, M. Hirano, and H. Hosono, "Heteroepitaxial growth of single-phase Zincblende ZnS films on transparent substrates by pulsed laser deposition under $\mathrm{H}_{2} \mathrm{~S}$ atmosphere", Solid State Commun., Vol.124, pp. 411, 2002

[4]. Tao-Yu Zhou, Xin-Yuan, Jing-Ming Hong, Xin-Quan Xin, "Room-temperature solid-state reaction to nanowires of zinc sulfide”Mater. Lett., Vol. 60, pp. 168-172 2006

[5]. M.J.Nurhidayatullaili, B. Samira, and B.A.H. Sharifah, "Recent advances in heterogeneous photocatalytic decolorization of synthetic dyes,” The Scientific World Journal., Vol. 2014, pp.25, Article ID 692307, 2014

[6]. Pramod Gopinathan Nair, Swathy Vijayakumar, Teena Lisluke, Menacheri Sunil Paul Mathew, Charuvila Thankappan Aravindakumar "Degradation of dyestuff pollutant sudan I using advanced oxidation process," Journal of Water Resource and Protection., Vol.6, pp.12761283,2014

[7]. Montazerozohori M, Hasanalian J. "Kinetics of photocatalytic decolorization of paramagenta at buffer solutions using nanotitanium dioxide under aerobic condition",Environmental Progress \& Sustainable Energy., Vol.32, pp. 1061-1065, 2013

[8]. Kwang-Ho-Choo,Ran-Tao,'Use of photocatalytic membrane reactor for the removal of natural organic mater in water:Effect of photoinduced desorption and ferrihydrate adsorption,"J.Membrane science.,Vol.322, pp. 368-3749, 2018

[9]. G.Cappelletti , C.Bianchi , L. Ardizzone, "Nano-titania associated photoreaction of $\mathrm{Cr}(\mathrm{VI})$ the role of the different $\mathrm{TiO}_{2}$ polymers,S. Appl. Catal. B Environ., Vol.78, pp. 193-201, 2008

[10]. Tom Van Gerven, Guido Mul, Jacob Moulijn, Andrzej Stankiewicz,"A review of intensation of photocatalytic process", A. Chem. Eng. Process, Vol.46, pp.781-789, 2007

[11]. Herrmann, J.M, "Heterogeneous photocatalysis: state of the art and present applications", Top. Catal., Vol.34, pp.49-65, 2005

[12]. Xueting chang, Zhongliang Li, Xinixin Zhai, Shibin Sun, Danxia Gu, Lihua Dong, Yansheng Yin and Yanqiu Zhu,"Efficient synthesis of sunlight-driven ZnO-based heterogeneous photocatalysts," Mater. Des. Vol.98, pp.324-332, 2016

[13]. A.K.Kole, S.Gupta, P.Kumphakar, P.C.Ramamurthy,"Nonlinear optical second harmonic generation in ZnS quantum dots and observation on optical properties of ZnS /PMMA nanocomposites," Opticscommun.,Vol.313, pp.231-237,2014

[14]. M.Navaneethan, J.Archana, K.D.Nisha, Y.Hayakawa, S.Ponnusamy, C.Muthamizhchelvan, "Temperature dependence of morphology, Structural and Optical Properties of ZnS nanostructures synthesized by wet chemical rout," J.Alloys compd., Vol.506, pp.249-252,2010

[15]. J.C.Sanchez-Lopez, A.Fernandez, "The gas-phase condensation method for the preparation of quantum-sized ZnS nanoparticles,"Thin solid films., Vol.317, pp.497-499,1998

[16]. Hassan Ali, S.Karim, M.A.Rafiq, K.Maaz, Atta ur Rahman A.Nisar,M.Ahmad, "Eletrical conduction mechanism in ZnS nanoparticles,"J.Alloy.Compd.,Vol.612, pp.64-68, 2014

[17]. Lihong-Dong,Ying.Chu,Yanping-.Zhang,"microemulsion-medicated solvothermal synthesis of ZnS nanowires”.Matt.Lett., Vol.61, pp.46514654,2007

[18]. Jingang Zhao,R.enming Liu, "Surfactant -free hydrothermal synthesis and optical properties of ZnS solid microspheres",Mater.Lett., Vol.124, pp.239-241,2014

[19]. P.K.Ghosh,U.N.Maiti,S.Jana,K.K.Chattopadhyay, "Field emission from ZnS nanorods synthesized by radio frequency magnetron sputtering technique, “Appl.Surf.Sci.,Vol. 253, pp.1544-1550,2006

[20]. Wei.Zhang, Xianghua Zeng,Hongetei Liu, Junfeng Lu, "Synthesis and investigation of blue and green emission of ZnS ceramics,'Lumin.,Vol.134, pp.498-503,2013

[21]. Zhiyuan Ye, Linyan Kong, Feng Chen, Zhigang Chen, Yun Lin Chengbao Liu "A comparative study of photocatalytic activity of ZnS photocatalyst for degradation of various dyes",optic., Vol.164, pp.345-354,2018

[22]. Fengjuan Chen, Yali Cao, Dianzeng Jia," A facile route for the synthesis of ZnS rods with excellent photocatalytic Activity," Chemical Engineering Journal., Vol.234 pp.223-231,2013

[23]. Mohd Mubashshir Hasan Farooqi, Rajneesh K. Srivastava”, Structural, optical and photoconductivity study of ZnS nanoparticles synthesized by a low temperature solid state reaction method Structural, optical and photoconductivity study of ZnS nanoparticles synthesized by a low temperature solid state reaction method',Material science in semiconductor processing.,Vol.,20, pp.61-67, 2014

[24]. G. G. Ramteke1, A. S. Lanje, D. M. Pimpalshende,"Structural and Optical Performance of ZnS Nanoparticles Synthesized via Chemical Route",IJSRPAS.,Vol.6, Issue 3,pp.69-74, 2018.

[25]. P.P. Subha and M.K. Jayaraj, "Solar photocatalytic degradation of methyl orange dye using $\mathrm{TiO}_{2}$ nanoparticles synthesised by sol_gel method in neutral medium,"Joun.experi.nanosci., Vol.10, pp.1106-1115, 2015

[26]. L.P.Wang, G.Y.Hong,"A new preparation of Zinc Sulfide nanoparticles by solid state method at low temperature” Mater.Res.Bull., Vol.35, pp.695-701,2000

[27]. M.Jothibas, S.Johnson Jeyakumar, C.Manoharan, I. Kartharinal Punithavathy, P.Praveen, J.Prince Richard, "Structural and optical properties of zinc sulphide nanoparticles synthesized via solid state reaction method," J.Mater. Sci: Mater. Electron. Vol.28, Issue.2, pp.1889-1894, 2017

[28]. Zhengto.Deng, Hao Yan,Yan Liu, "Controlled colloidal growth of ultrathin single -crystal ZnS nanowires with a magic size diameter," Angew.chem.int.ed., Vol.49, pp.8695-8698, 2010.

[29]. C.Manoharan, M.Jothibas, S.Johnson Jeyakumar, S.Dhanapandian, "Structural, optical and electrical properties of $\mathrm{Zr}$ doped $\mathrm{In}_{2} \mathrm{O}_{3}$ thin films", Spectrochim.Acta part A Mol.Spectrosc, Vol.145, pp.47-53, 2015

[30]. J.Prince Richard, I.Kartharinal Punithavathy, S.Johnson Jeyakumar, M.Jothibas, P.Praveen, "Effect of morphology in the photocatalytic degradation of methyl violet dye using ZnO nanorods," J.Mater.Sci: Mater. Electron, Vol. 28, Issue. 5, pp.4025-4034,2017 
[31]. Z.Yamlahi Alami, M.Salem, M. Gaidi, J.Elkhamkhami,"Effect Of Zn concentration on structural and optical proprieties of ZnO thin films deposited by spray pyrolysis", Advanced Energy: An International Journal, Vol. 2, 2015

[32]. R.Sathish Kumar, S.Johnson Jeyakumar, M.Jothibas, I.Kartharinal Punithavathy, J.Prince Richard, "Influence of molar concentration on structural, optical and magnetic properties of NiO nanoparticles," J Mater Sci: Mater Electron.,2017,DOI 10.1007/s10854-017-7456-7

[33]. Suchitra Sen, S. K. Halder, and S. P. Sen Gupta "An X-Ray Line Broadening Analysis in the Vacuum-Evaporated Silver Films," Jour. Phys. Soc. Japan, Vol.38, Issue. 6, pp. 1641-1947, 1975

[34]. M.Jothibas, C.Manoharan, S.Dhanapandian, S.Johnson Jeyakumar,'Influence of precursor concentration on sprayed In ${ }_{2} \mathrm{O}_{3}$ thin films", Asian J. Chem., Vol.25, pp.S59-S64,2013

[35]. Yuri.V.B.de,Santana, Cristiane W.Raubach, Meteus M.Ferrer,Felipe La.Porta,Julio R.Sambrano,V.M.Longo,E.R.Leitie,E.Longo, "Experimental and theoretical studies on the enhanced photoluminescence activity of Zinc Sulfide with a capping agent”,J.Appl.Phys., Vol.110, pp.12350712315,2011

[36]. Felipe A. La Porta, Mateus M. Ferrer, Yuri V. B. de Santan , Cristiane W. Raubach , Valéria M. Longo , Júlio R. Sambrano , Elson Longo, Juan Andrés , Máximo S. Lie and José .Varela "Towards an Understanding on the Role of Precursor in the Synthesis of ZnS Nanostructures,"J.alloys Curr.phys.chem.,Vol. 3, pp.378-385, 2013

[37]. Felipe A. La Porta, Mateus M. Ferrer, Yuri V. B. de Santan, Cristiane W. Raubach , Valéria M. Longo,Júlio R.Sambrano, Elson Longo, Juan Andrés, Máximo S.Lie and José .Varela, "Synthesis of wurtzite ZnS nanoparticles using the microwave assisted solvothermal method,”Journal of Alloys and Compounds., Vol.556, pp.153-159, 2013

[38]. S.S.Kumar, M.A..Khadar, S.K. Dhara, T.K. Ravindran, K.G.M. Nair, "Photoluminescence and Raman studies of ZnS nanoparticles implanted with $\mathrm{Cu}^{+}$ions", Nucl. Instrum. Meth. B., Vol. 251 pp.435,2004

[39]. P.H. Borse, N. Deshmukh, R.F. Shinde, S.K. Date, S.K. Kulkarni, "Luminescence quenching in ZnS nanoparticles due to Fe and Ni doping," J. Mater. Sci., Vol.34, pp.6087, 1999

[40]. H.Y. Lu, S.Y. Chu, S.S. Tan, "The characteristics of low-temperature-synthesized ZnS and ZnO nanoparticles," J.Cryst. Growth.,Vol.269 pp.385,2004

[41]. Palvinder Kaur, Sanjeev Kumar, Chi-Liang Chen , Kai-Siang Yang,Da-Hua Wei , Chung-Li ss Dong, C. Srivastava , S.M. Rao", Gd doping induced weak ferromagnetic ordering in $\mathrm{ZnS}$ nanoparticles synthesized by low temperature co-precipitation technique" Materials Chemistry and Physics xxx, pp.1-7,2016

[42]. G.S.Lotey, Z.Jindal, V.Singhi, N.K.Verma, "Structural and photoluminescence properties of Eu doped ZnS nanoparticles,"Mater. Sci. Semicond. Process., Vol.16 pp.2044, 2013

[43]. V.D.Mote, Y.Purushotham, B.N.Dole, "Structural, morphological and optical properties of Mn doped ZnS nanocrystals,” Cerâmica.,Vol. 59 pp.614-619, 2013

[44]. Xueting Chang, Zhongliang Li, Xinxin Zhai, Shibin Sun, Danxia Gu, Lihua Dong, Yansheng Yin, Yanqiu Zhu,"Efficient synthesis of sunlightdriven ZnO based heterogeneous photocatalysts," Mater. Des., Vol.98, pp.324-332, 2016.

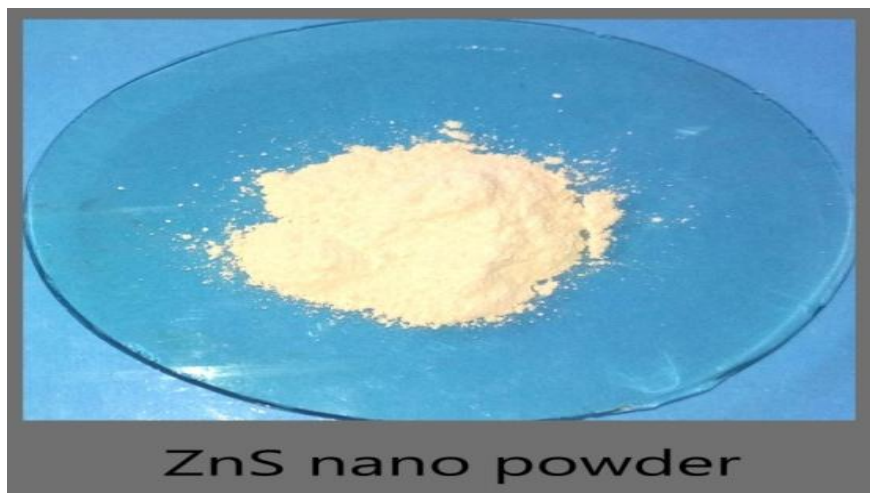

Figure 1. Pure ZnS nanoparticles

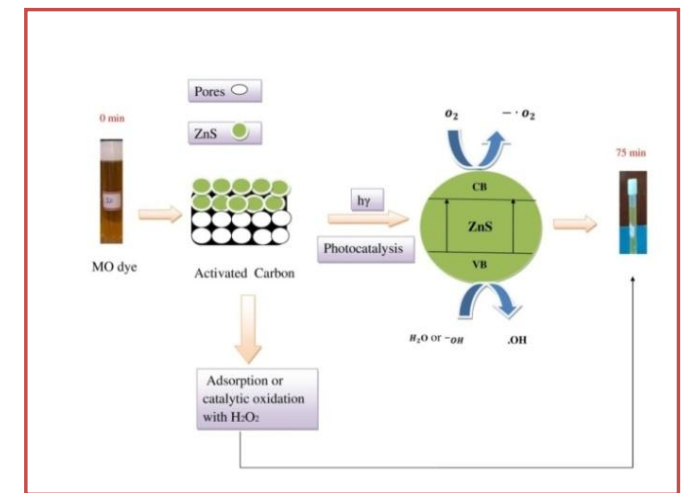

Figure 2. The graphical abstract of MO dye using $\mathrm{ZnS}$ nanoparticles. 


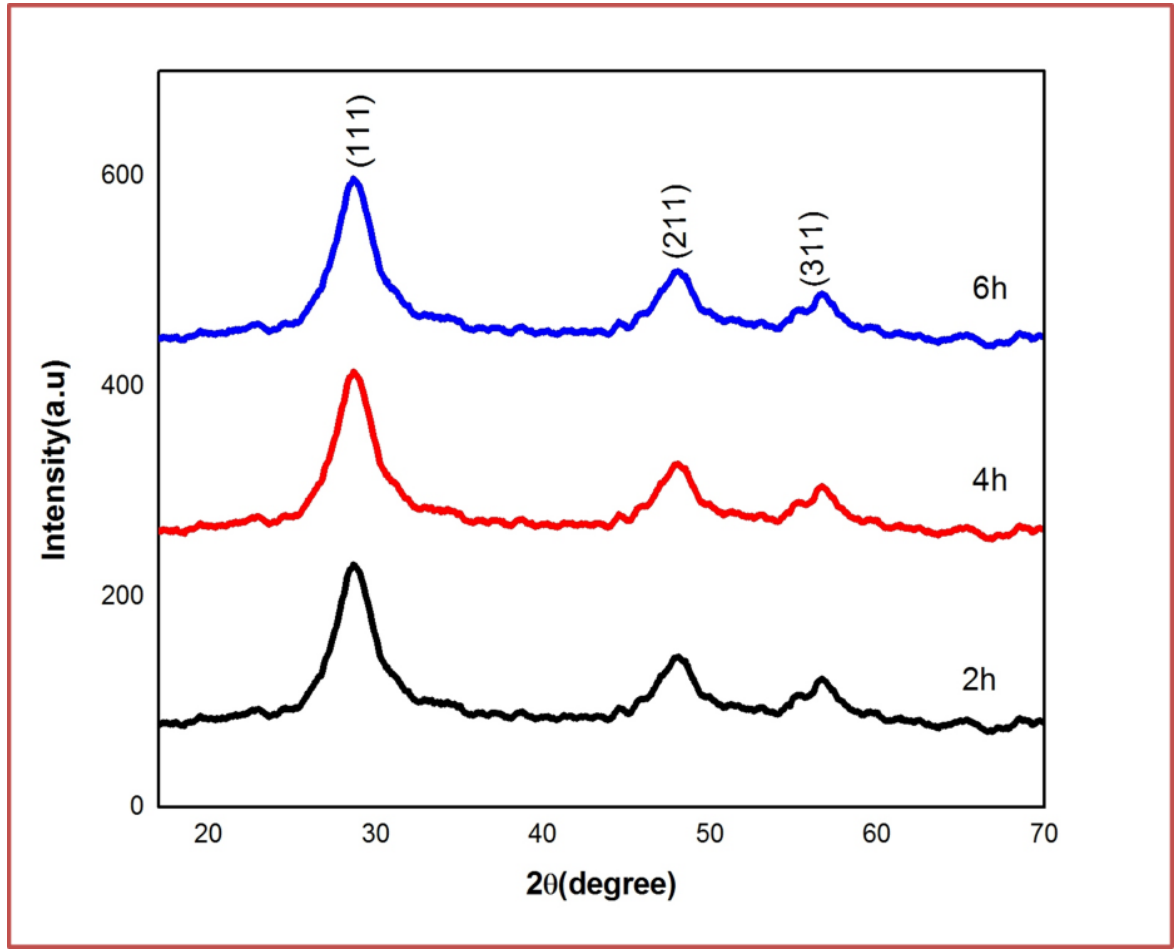

Figure 3. X-ray diffraction of $\mathrm{ZnS}$ nanoparticles at different hours

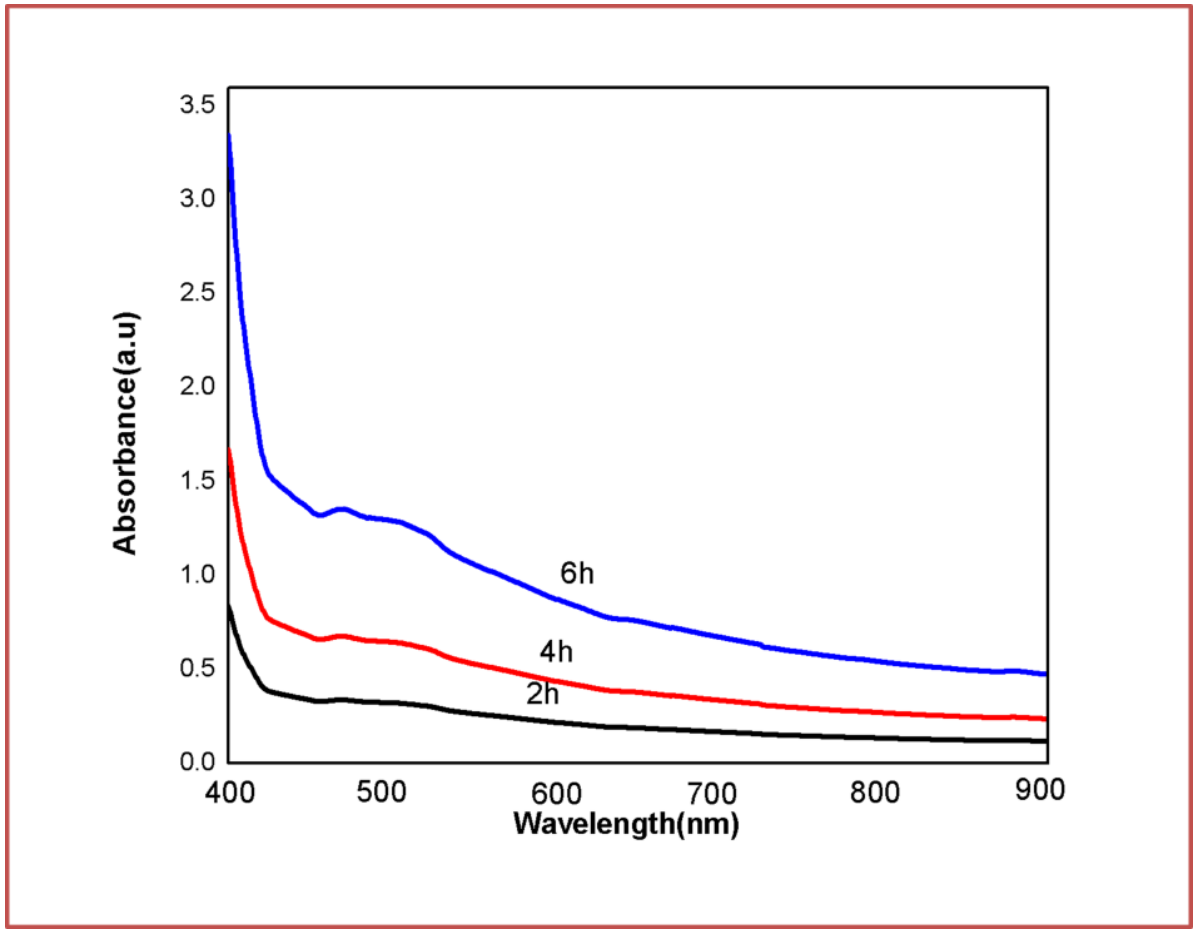

Figure 4. Optical absorption spectra of $\mathrm{ZnS}$ nanoparticles. 


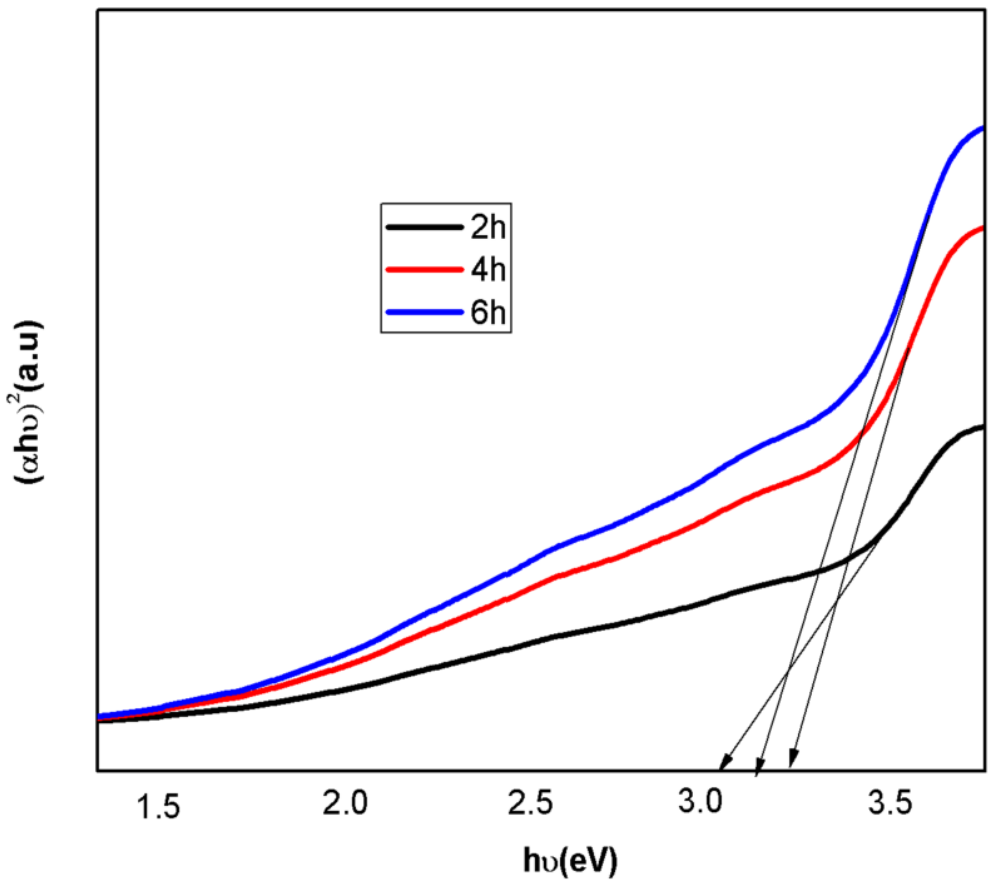

Figure 5. The plot of $(\alpha h \gamma)^{2}$ versus h $\gamma$ for $\mathrm{ZnS}$ nanoparticles.

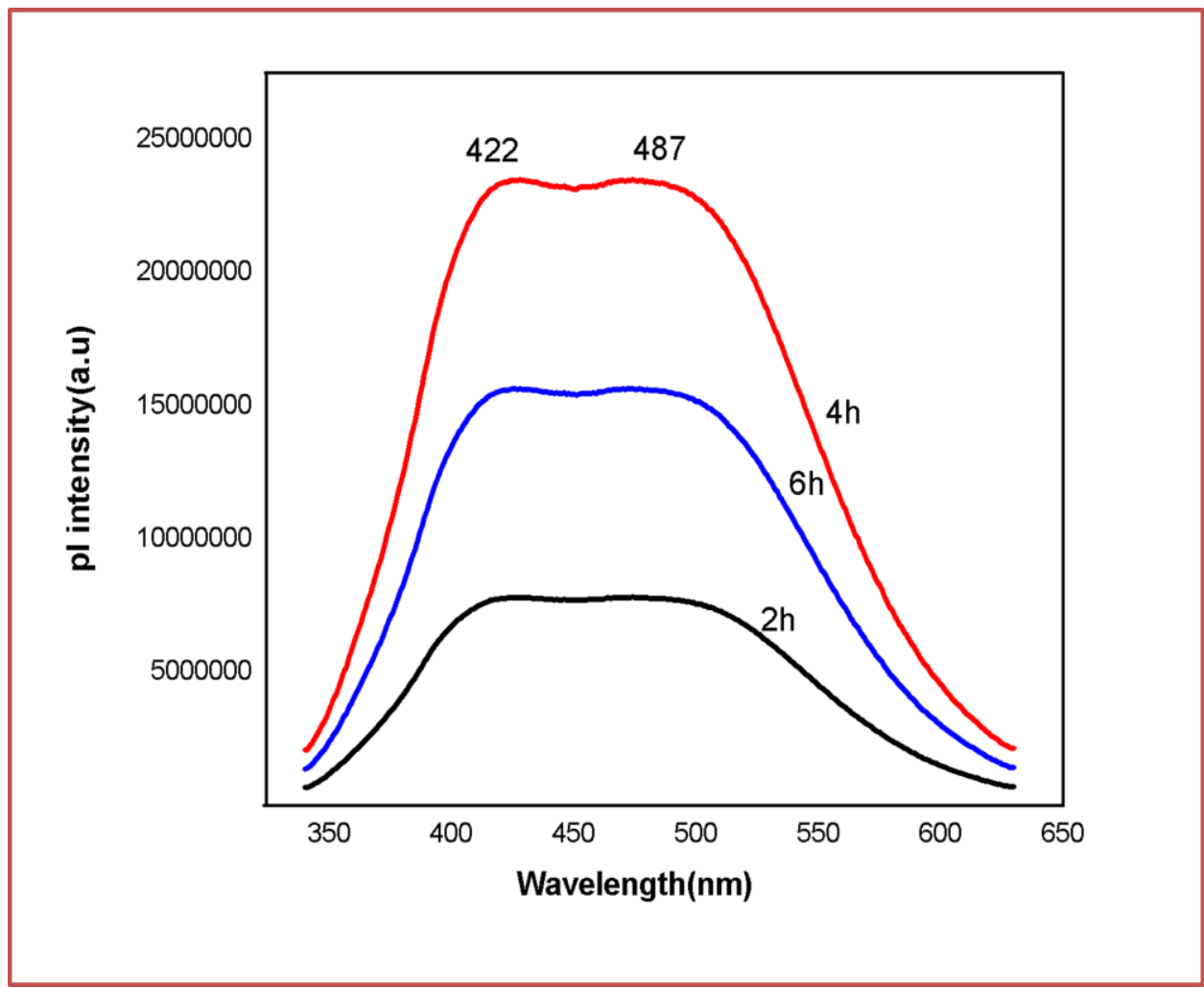

Figure 6. Photoluminescence emission spectrum of $\mathrm{ZnS}$ nanoparticles excited at $325 \mathrm{~nm}$ 


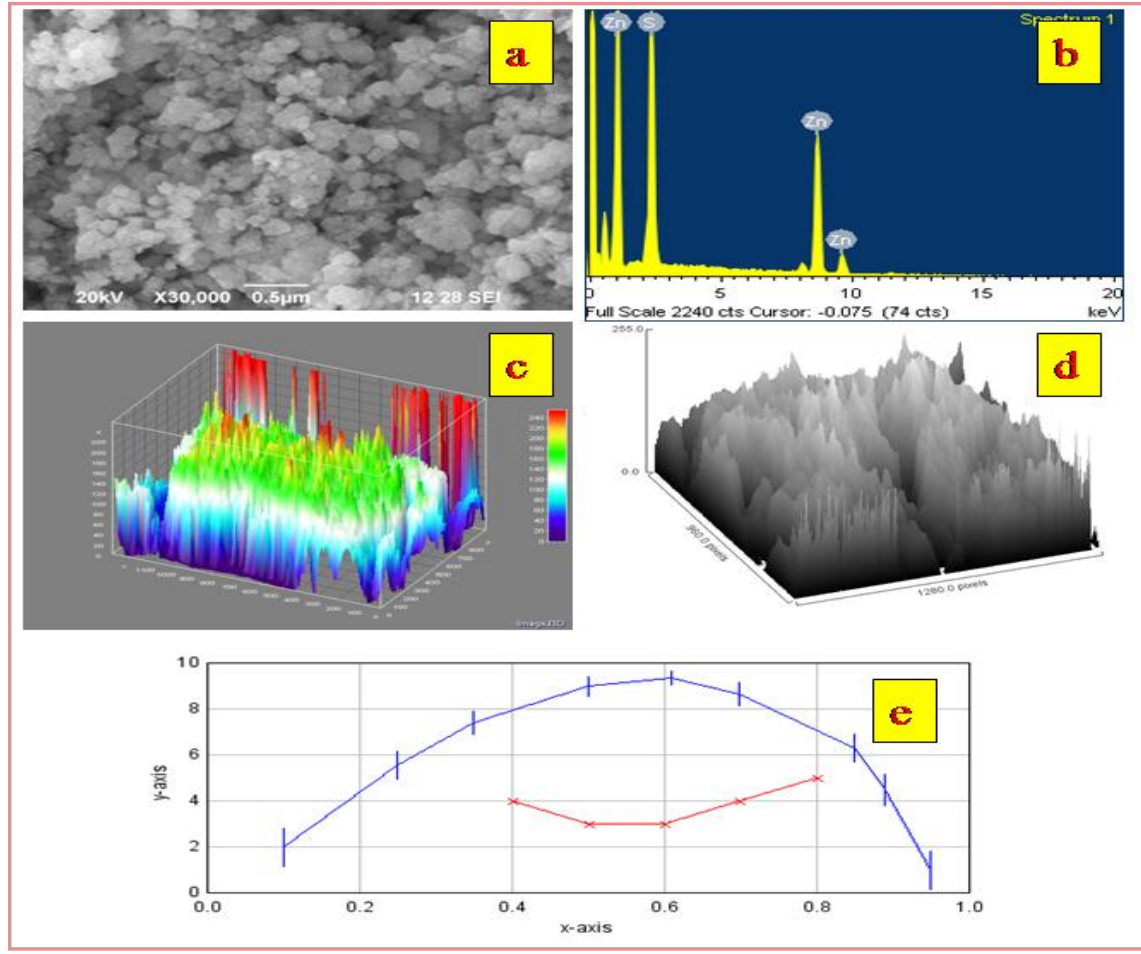

Figure 7 (a). SEM image (a) pure, (b) EDs spectrum and (c-e) Surface Occupancy Plot (SOP) ZnS nanoparticles.
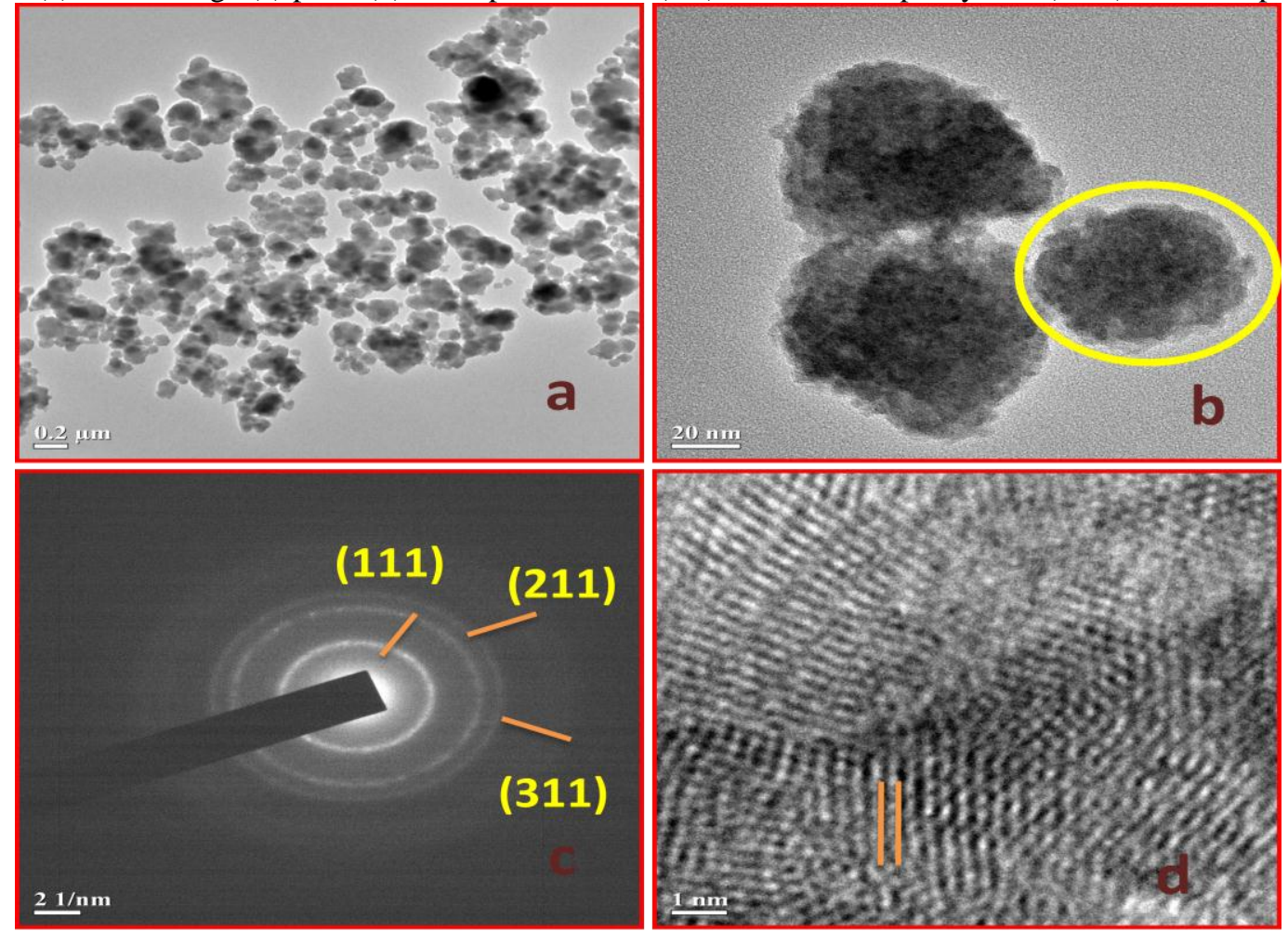

Figure 8. TEM images of ZnS nanoparticles (a-b), corresponding SAED pattern (c) and (d) frindge pattern. 


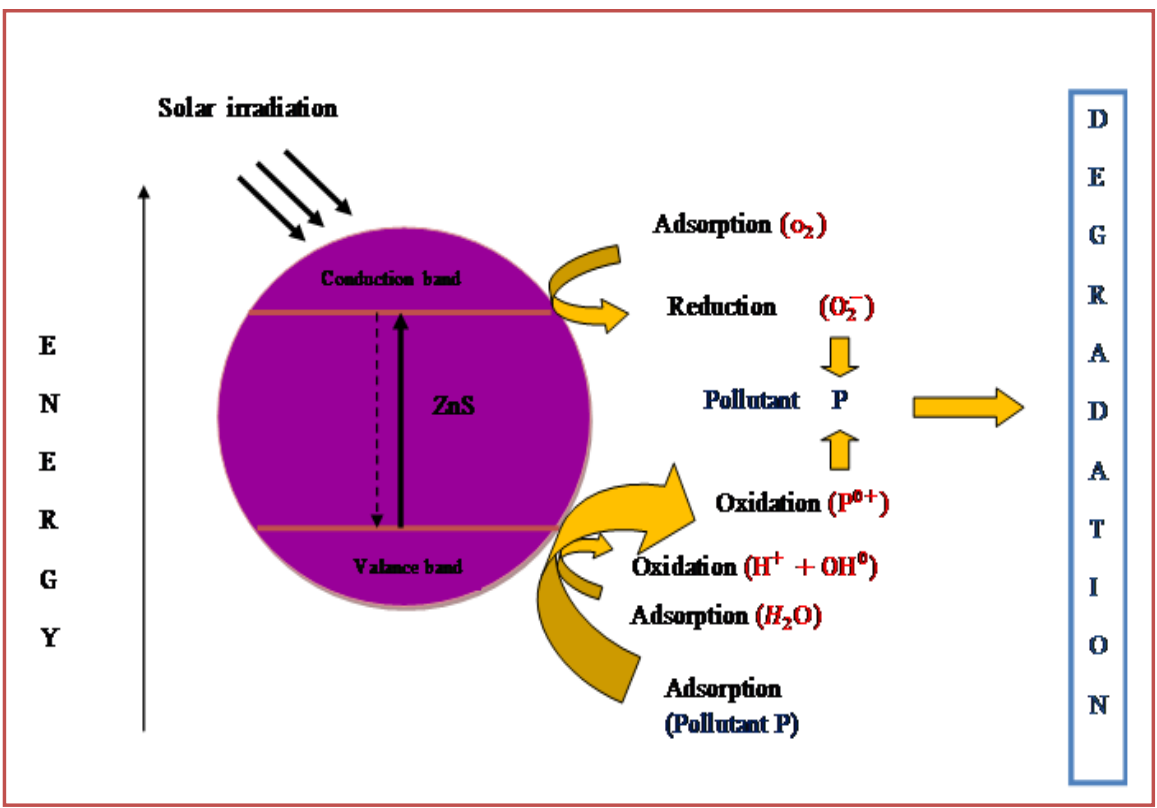

Figure 9. A possible photocatalytic mechanism for degradation of MO dyes by $\mathrm{ZnS}$ nanoparticles under solar light irradiation.

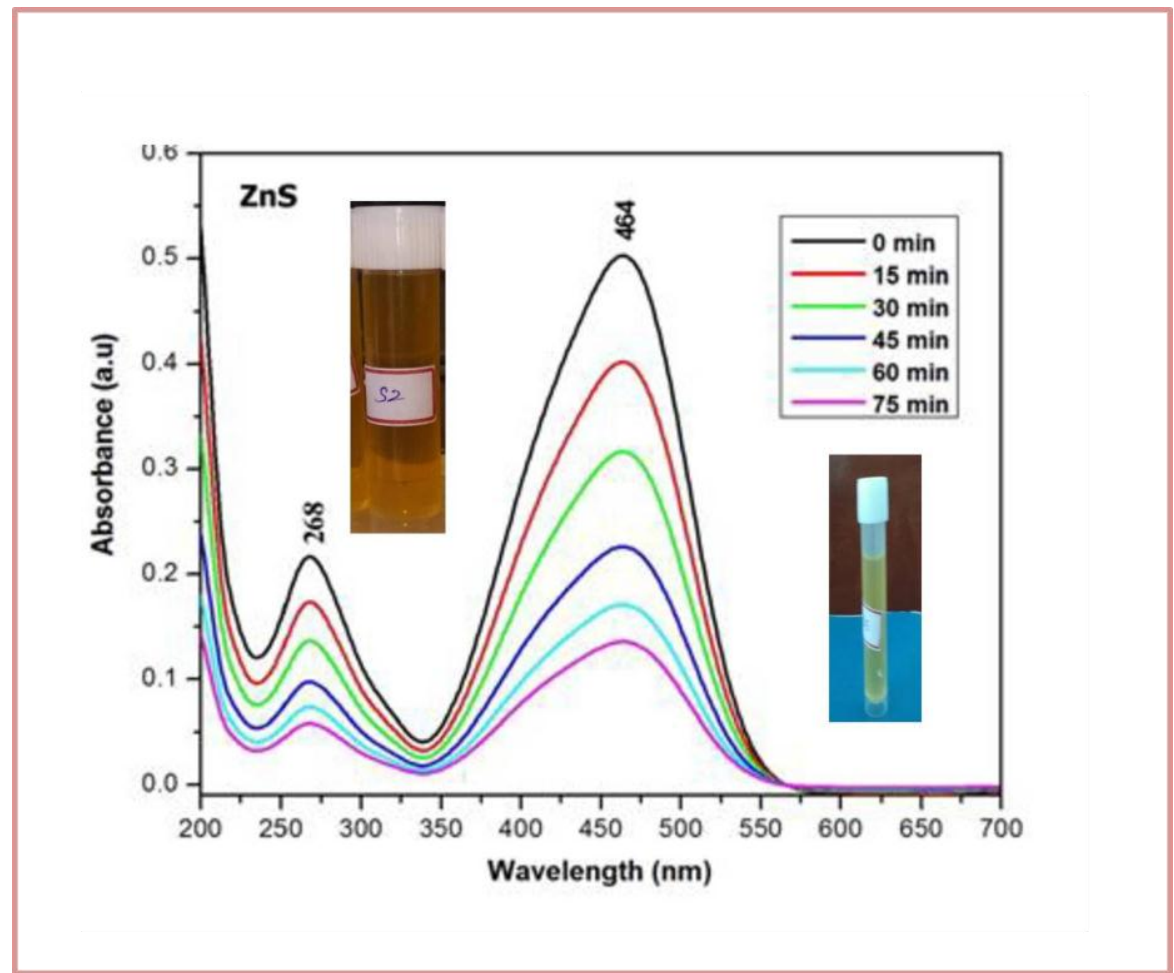

Figure 10. UV-Vis absorption spectra of MO with respect to irradiation time using ZnS Photocatalyst. 


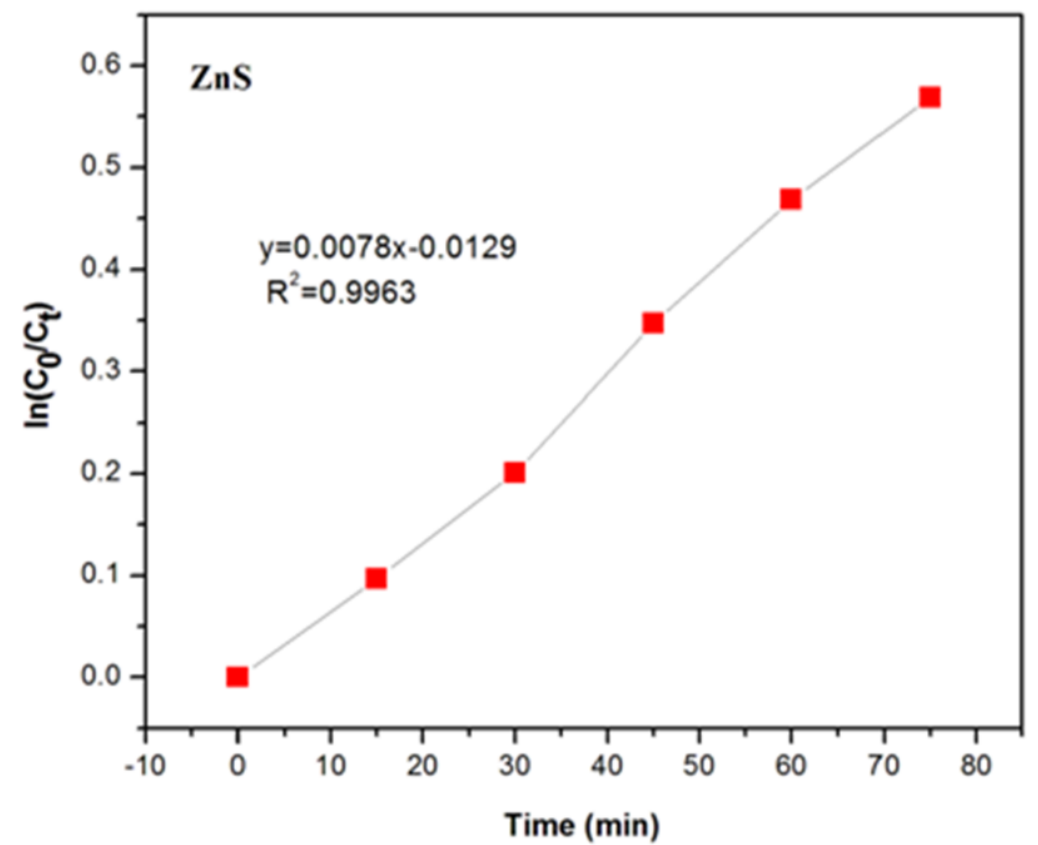

Figure 11. Relation curve between $\ln \left(\mathrm{C}_{0} / \mathrm{C}_{\mathrm{t}}\right)$ and time $(\mathrm{t})$.

Table 1.Structural properties of $\mathrm{ZnS}$ nanoparticles

\begin{tabular}{|c|c|c|c|c|c|c|c|c|c|c|}
\hline $\begin{array}{c}\text { Sample } \\
\text { (hrs) }\end{array}$ & $\begin{array}{c}2 \Theta \\
\text { degree }\end{array}$ & $\begin{array}{c}\mathrm{D} \\
\text { space }\end{array}$ & FWHM & $\operatorname{Cos} \theta$ & $\begin{array}{c}\text { Crystal } \\
\text { Size } \\
(\mathrm{nm})\end{array}$ & $\begin{array}{c}\text { Average } \\
\text { Crystal } \\
\text { Size } \\
(\mathrm{nm})\end{array}$ & $\begin{array}{c}\text { Dislocation } \\
\text { density } \\
\delta \times 10^{14} \\
\text { lines } / \mathrm{m}^{2}\end{array}$ & $\begin{array}{c}\text { Micro } \\
\text { strain } \\
\varepsilon \\
\left(\times 10^{-3}\right)\end{array}$ & $\begin{array}{l}\text { Lattice } \\
\text { Constant } \\
\text { (A) }\end{array}$ & $\begin{array}{l}\text { Average } \\
\text { Lattice } \\
\text { constant } \\
(\AA)\end{array}$ \\
\hline 2 & $\begin{array}{l}28.7083 \\
47.9000 \\
56.6250\end{array}$ & $\begin{array}{l}3.1071 \\
1.8975 \\
1.6241\end{array}$ & $\begin{array}{l}2.6167 \\
0.9319 \\
0.8803\end{array}$ & $\begin{array}{l}0.9687 \\
0.9319 \\
0.8803\end{array}$ & $\begin{array}{l}3.2717 \\
3.7814 \\
4.8313\end{array}$ & 3.97 & $\begin{array}{l}9.3416 \\
6.9943 \\
4.2842\end{array}$ & $\begin{array}{l}0.0110 \\
0.0095 \\
0.0074\end{array}$ & $\begin{array}{l}5.4925 \\
5.3669 \\
5.3864\end{array}$ & 5.4152 \\
\hline 4 & $\begin{array}{l}28.3166 \\
47.5375 \\
56.4125\end{array}$ & $\begin{array}{l}3.1492 \\
1.9112 \\
1.6300\end{array}$ & $\begin{array}{l}2.7330 \\
2.6750 \\
2.1000\end{array}$ & $\begin{array}{l}0.9696 \\
0.9155 \\
0.8812\end{array}$ & $\begin{array}{l}3.1977 \\
3.3879 \\
4.4814\end{array}$ & 3.68 & $\begin{array}{l}9.7796 \\
8.7122 \\
4.9197\end{array}$ & $\begin{array}{l}0.1132 \\
0.0106 \\
0.0080\end{array}$ & $\begin{array}{l}5.4545 \\
5.4056 \\
5.4063\end{array}$ & 5.4221 \\
\hline 6 & $\begin{array}{l}28.2916 \\
47.4250 \\
56.4125\end{array}$ & $\begin{array}{l}3.1188 \\
1.9055 \\
1.6270\end{array}$ & $\begin{array}{l}2.5833 \\
2.4500 \\
2.1250\end{array}$ & $\begin{array}{l}0.9690 \\
0.9146 \\
0.8808\end{array}$ & $\begin{array}{l}3.1103 \\
3.6974 \\
4.4290\end{array}$ & 3.81 & $\begin{array}{l}9.1216 \\
7.3145 \\
5.0978\end{array}$ & $\begin{array}{l}0.0109 \\
0.0097 \\
0.0081\end{array}$ & $\begin{array}{l}5.4018 \\
5.3896 \\
5.3962\end{array}$ & 5.3958 \\
\hline
\end{tabular}


Table 2. Calculated band gap energies of $\mathrm{ZnS}$ nanoparticles at different hours

\begin{tabular}{|c|c|}
\hline ZnS & Band gap energy $(\mathbf{e V})$ \\
\hline $2 \mathrm{~h}$ & 3.41 \\
\hline $4 \mathrm{~h}$ & 3.66 \\
\hline $6 \mathrm{~h}$ & 3.83 \\
\hline
\end{tabular}

Table 3. EDX pattern of $\mathrm{ZnS}$ nanoparticles

\begin{tabular}{|c|c|c|}
\hline Element & Weight percentage & Atomic percentage \\
\hline $\mathbf{Z n}$ & 24.91 & 40.34 \\
S & 75.09 & 59.66 \\
Total & $\mathbf{1 0 0}$ & $\mathbf{1 0 0}$ \\
\hline
\end{tabular}

Table 4. The effect of methyl orange (MO) dye degradation by $\mathrm{ZnS}$ photocatalysts

\begin{tabular}{|c|c|}
\hline Time (min) & \% degradation of MO dye \\
\hline 0 & 0 \\
\hline 15 & 20 \\
\hline 30 & 36.99 \\
\hline 45 & 55.00 \\
\hline 60 & 65.99 \\
\hline 75 & 72.99 \\
\hline
\end{tabular}

\section{AUTHORS PROFILE}

Dr. M.Jothibas has completed her Ph.D degree in the year 2014 from Annamalai University, Annamalai nagar-608002, Tamil Nadu. He has published more than 22 papers in international peer reviewed journal and attended 35 national and international conferences. Presently he is working as an Assistant professor of Physics, TBML College, Porayar-609307, Tamil Nadu, India. The area of research is, Thin film, Nanomaterial Science, Nanoelectronics, Biophysics and Nanosensors. He has 7 years of teaching and research experience in PG level. Currently, four students are perusing $\mathrm{Ph}$. D. under his supervision.

Ms. S. Suganya perused B.Sc \& M. Sc. (Physics), in Dharamapuram Adhinam Arts \& sciences College, Mayiladuhurai-609001, Tamil Nadu, India. she perused M.Phil, and currently pursuing his Ph.D degree in Full-Time in TBML College, Porayar-609307, Tamil Nadu, India (affiliated to Bharathidasan University). His main research work focuses on Nanaomaterial Science and characterization in Sol-Gel method.

Mr. A. Muthuvel perused B.Sc \& M.Sc. (Physics) in Government Arts \& sciences College, C. Muttlur608102, Tamil Nadu, India (affiliated to Thiruvalluvar University). He is completed M.Phil, degree in the Annamalai University, Annamalai nagar-608002, Tamil Nadu, India. He is currently pursuing his Ph.D degree in Part-Time as a Part- Time in TBML College, Porayar-609307, Tamil Nadu, India (affiliated to Bharathidasan University). The current research focuses on synthesis, characterizations of Nanoparticles and its bio-medical application. 